\title{
Overview of the AVT-191 Project to Assess Sensitivity Analysis and Uncertainty Quantification Methods for Military Vehicle Design
}

\author{
John A. Benek \\ Air Force Research Laboratory, Wright-Patterson AFB, OH, 45433 \\ James M. Luckring ${ }^{\dagger}$ \\ NASA Langley Research Center, Hampton, VA, 23681
}

\begin{abstract}
A NATO symposium held in 2008 identified many promising sensitivity analysis and uncertainty quantification technologies, but the maturity and suitability of these methods for realistic applications was not known. The STO Task Group AVT-191 was established to evaluate the maturity and suitability of various sensitivity analysis and uncertainty quantification methods for application to realistic problems of interest to NATO. The program ran from 2011 to 2015, and the work was organized into four discipline-centric teams: external aerodynamics, internal aerodynamics, aeroelasticity, and hydrodynamics. This paper presents an overview of the AVT-191 program content.
\end{abstract}

\section{Nomenclature}

Symbols

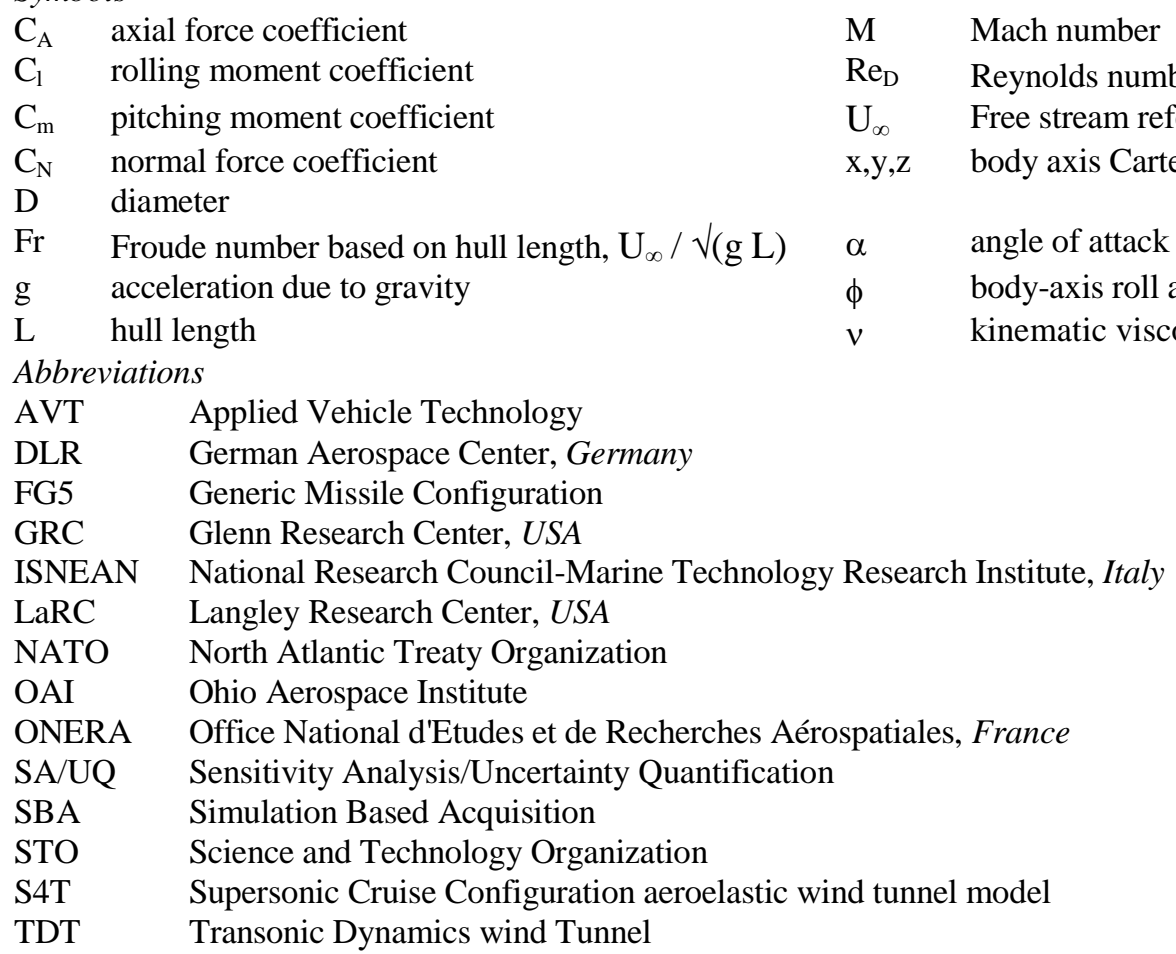

\footnotetext{
* Senior Scientist for Computational Fluid Dynamics, Aerospace Systems Directorate, john.benek@us.af.mil, AIAA Fellow.

${ }^{\dagger}$ Senior Research Engineer, Configuration Aerodynamics Branch, james.m.luckring@nasa.gov, AIAA Associate Fellow.
} 


\section{Introduction}

F or over a decade, acquisition strategy has been shifting toward a model-test-model paradigm (i.e., Simulation Based Acquisition, SBA). The basic concept is that extensive modelling of new systems will allow expansion of the design space and permit revolutionary new technologies to be incorporated in a more timely manner, reduce development cycle time and cost, and field more reliable systems. A critical element to implementing this concept is the extensive use of high-fidelity, physics-based, modelling and simulation to supplement and/or replace the groundtest data that is typically used in system design and development. While such numerical simulations can produce databases more rapidly and less expensively than ground testing, to be most effective, the uncertainty of the computations must be estimated. In the early $2000 s$, the procedures for making such estimates were immature at best or unknown to the general community at worst.

The Scientific and Technology Organization (STO) is a subsidiary body of NATO whose charter is to address the collective science and technology needs of NATO. The STO was established in 2012 from the Research and Technology Organization (RTO) which, in turn, was created in 1996 by a restructuring of the Advisory Group for Aerospace Research and Development (AGARD). AGARD was founded in 1952 by Theodore von Karman with many of the same objectives sustained through the RTO and the STO. The STO is the largest such body in the world, embracing 28 NATO nations, approximately 38 NATO partner nations, and over 3000 scientists and engineers. The STO not only sustains activities of continuing interest to NATO but also initiates new activities in in response to evolving system requirements and technological capabilities.

The STO established a task group, AVT-147 to make an assessment of computational uncertainty estimation procedures. The task group compiled state-of-the-art methods for assessing computational uncertainty, to identify issues associated with these methods and their implementation, and to establish how the methods were being applied. To this end, a Symposium on Computational Uncertainty in Military Vehicle Design was organized and held in Athens, Greece on 3-6 December of 2007. The symposium focused on five topics:

(1) Uncertainty identification and quantification

(2) Numerical accuracy

(3) Code verification

(4) Code validation

(5) Uncertainty propagation methods.

The Symposium had four Plenary Sessions and 64 technical papers on these five topics. One of the major conclusions of the Symposium was that a large number of methods were being developed, but the maturity and suitability of these methods for realistic applications was not established.

Therefore, a second task group was organized to evaluate the maturity and suitability of various sensitivity analysis and uncertainty quantification methods on realistic problems of interest to NATO. Because of the broad scope of this subject area, the AVT-191 task group, Application of Sensitivity Analysis and Uncertainty Quantification to Military Vehicle Design, focused on variational (aleatory) uncertainties (i.e., uncertainties whose distribution functions are known). Thus, the uncertainty methods are applied to problems in which the uncertainty distributions of key simulation inputs are given and the task is to use high fidelity simulations coupled with selected uncertainty methodologies to compute the distribution of specified output quantities.

Proceedings from the symposium ${ }^{1}$ were published in 2008 , and the complete results from task group AVT-191 are in the process of being published as a NATO technical report. ${ }^{2}$ Two special sessions containing 11 papers have been established at this conference to highlight some of the results from the AVT-191 program. This paper provides an overview of the AVT-191 program content. This paper serves as an introduction to 9 papers with technical details of the AVT-191 activity (See, Table 1.). A second paper by the authors will summarize findings from the work. Content for this overview paper has been drawn from the NATO technical report ${ }^{2}$. 


\section{Scope of the Study}

The selection of model problems on which to evaluate the sensitivity analyses and/or uncertainty quantification methods (SA/UQ) methods was an important part of the effort. The task group determined that candidate model problems should possess four characteristics: First, the problems should be unclassified and unrestricted in order to attract the broadest number of participants and have the greatest effect on the community. Second, the problems should be interesting enough to maintain interest of the participants for the duration of the study and be relevant to current issues. Third, the problems should be as simple as possible to minimize the resources, both computational and manpower, required to exercise the various SA/UQ methods. However, the model problems must be sufficiently complex to be representative of a broad range of realistic applications. Fourth, the problems should have experimental data available to verify that the simulations used in the SA/UQ analyses are of acceptable accuracy.

Four disciplines were selected for model problems: external aerodynamic flow, aero-elasticity, hydrodynamic flow, and internal aerodynamic flow. These problems cover a broad range of flow physics, compressible and incompressible flows, and multidisciplinary flow related physics. They have a broad range of boundary conditions such as

Table 1. SA/UQ methods used in each paper.

\begin{tabular}{|c|c|c|}
\hline $\begin{array}{c}\text { Paper } \\
\text { Sequence }\end{array}$ & Discipline & SA/UQ Method \\
\hline \multicolumn{3}{|c|}{ Session APA-28 } \\
\hline 2 & $\begin{array}{c}\text { External } \\
\text { Aerodynamics }\end{array}$ & $\begin{array}{l}\text { Monte Carlo with surrogate model } \\
\text { Nonintrusive polynomial chaos }\end{array}$ \\
\hline 3 & & Sampling methods \\
\hline 4 & & Sampling methods \\
\hline 5 & $\begin{array}{c}\text { Internal } \\
\text { Aerodynamics }\end{array}$ & $\begin{array}{l}\text { Nonintrusive Polynomial Chaos } \\
\text { Intrusive Polynomial Chaos }\end{array}$ \\
\hline \multicolumn{3}{|c|}{ Session APA-40 } \\
\hline 1 & Aeroelasticity & Sampling methods \\
\hline 2 & & $\begin{array}{c}\text { Sampling methods } \\
\text { Proper Orthogonal Decomposition }\end{array}$ \\
\hline 3 & & Surrogate Modeling \\
\hline 4 & Hydrodynamics & $\begin{array}{l}\text { Nonintrusive Monte Carlo } \\
\text { Polynomial Chaos } \\
\text { Reduced order modeling }\end{array}$ \\
\hline 5 & & $\begin{array}{l}\text { Nonintrusive Monte Carlo } \\
\text { Polynomial Chaos } \\
\text { Reduced order modeling }\end{array}$ \\
\hline
\end{tabular}
constrained flow with finite boundaries, unconstrained flows with free boundaries, and coupled solid-fluid and fluidgas boundaries. Teams were formed around each discipline so that a range of SA/UQ methods could be assessed for each discipline and across disciplines. A summary of the methods used for each discipline is given in Table 1. Each discipline team was tasked with establishing their model problem/problems for analysis. A model problem was comprised of a configuration, a simulation technology (e.g., RANS methods), input variation parameters, and output variation parameters. The particular SA/UQ methods used to work the model problem were left to the discretion of the discipline team members.

\section{A. External Aerodynamics}

The external aerodynamics team focused on the Generic Missile Configuration, FG5 of ONERA ${ }^{3}$, Fig. 1, which consists of a tangent ogive cylinder with four aft mounted trapezoidal, $6 \%$ thick fins, oriented at $22.5^{\circ}$ to the vertical symmetry plane. (See Fig. 2.) Experimental force and moment data obtained at $\mathrm{M}=0.8$ and Reynolds numbers based on missile diameter of $\operatorname{Re}_{\mathrm{D}}=0.6 \times 10^{6}$ were provided from tests conducted in the ONERA S3MA wind tunnel and were made avail-

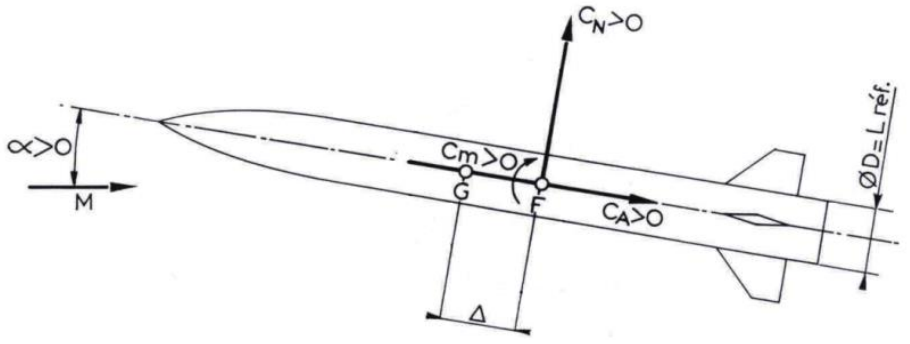

Figure 1. FG5 generic missile configuration. Side view. able to the AVT-191 Task Group by the Applied Aerodynamics Department of ONERA. The data included repeat 
alpha sweeps from a test executed 10 years previously. The agreement is very good. The geometry of the support sting was proved as a surface mesh. (See Fig. 3.)

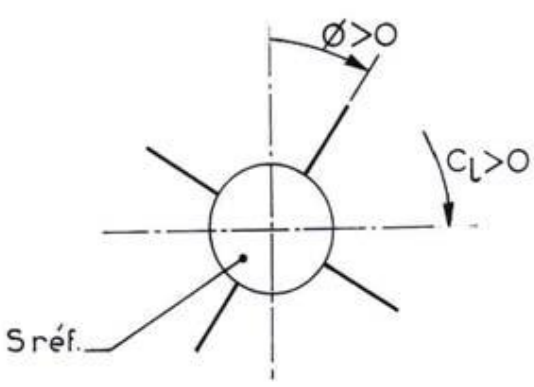

Figure 2. FG5 generic missile configuration. End view looking down stream.

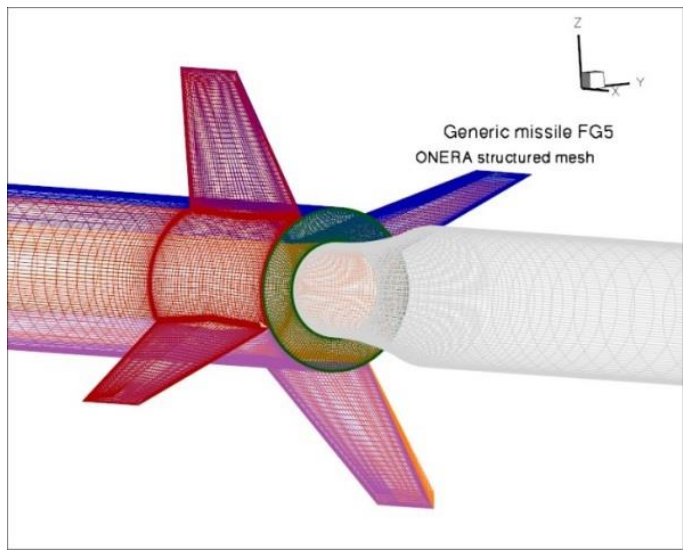

Figure 3. ONERA support sting geometry.

An example of the missile flow field is shown in Figure 4 at $\mathrm{M}=0.8, \mathrm{Re}_{\mathrm{D}}=0.6 \times 10^{6}$, and $\alpha=12^{\circ}$ from a deterministic RANS simulation ${ }^{4}$. The flow field is displayed with a ratio of total pressures in a body-axis crossflow plane near the trailing edge of the missile and shows a complex interaction of the fore body vortices with the fins as well as fin vortical flows. At this condition, the missile exhibited nonlinear force and moment trends with angle of attack.

The objective of the external aerodynamics model problem study was to determine the effect of input uncertainties in angle of attack, azimuthal position of the fins and deflection angle of fins from azimuthal planes on outputs of forces and moments. A reduced order model of the measured values of the forces and moments was also made available.

The External Aerodynamics Team was led by J. Peter of ONERA. Team members included J. Doty, University of Dayton, R. Graves of OAI, and S. Goertz of DLR. Summary results in these AIAA special sessions are provided by Peter et al. ${ }^{4}$, Doty ${ }^{5}$, and Graves ${ }^{6}$.

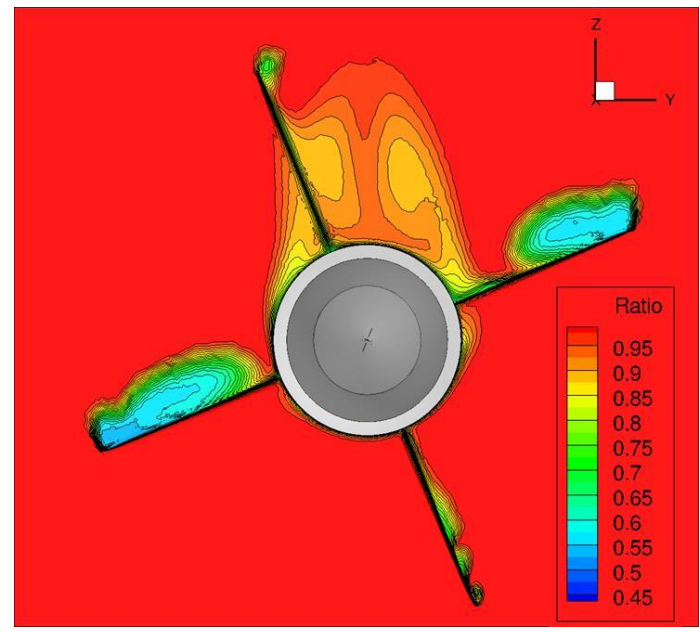

Figure 4. Deterministic missile flowfield simulation, $\mathrm{M}=0.8, \mathrm{Re}_{\mathrm{D}}=0.6 \times 10^{6}, \alpha=12^{\circ}$.

\section{B. Internal Aerodynamics}

The Internal Aerodynamics Team focused on the use of non-deterministic approaches coupled with high fidelity flow simulation methods to assess the effects of uncertainties of variable input parameters including inlet total pressure, static outlet pressure, and tip clearance, as well as compressor geometric variations such as leading-edge blade angle and trailing-edge blade angle caused by manufacturing tolerances on output parameters such as mass flow rate, isentropic efficiency, and pressure ratio. The configuration they chose to study was the NASA Rotor 37 compressor ${ }^{7}$, shown in Fig. 5.

An example of the rotor flow field is shown in Figure 6 from a deterministic RANS simulation ${ }^{8}$. The results show a shock-induced boundary layer separation at approximately mid chord of the blade as well as an interaction of the transonic shock from a leading blade with the leading-edge flow about a following blade.

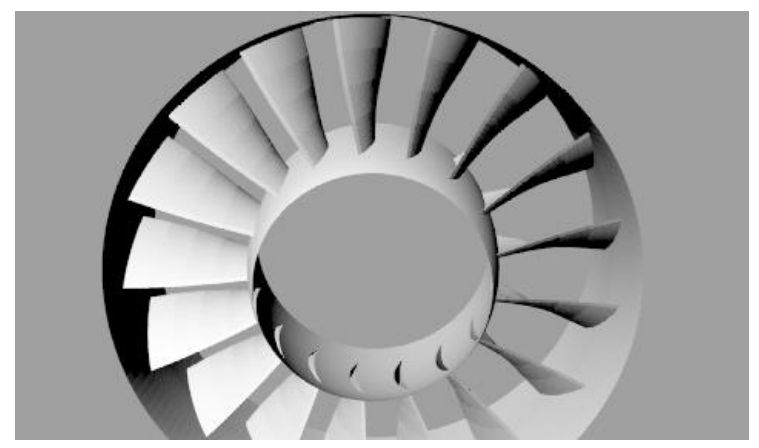

Figure 5. NASA Rotor 37 configuration. 
The objective of the internal aerodynamics model problem study was to determine the effect of both geometrical uncertainties and operational uncertainties on rotor performance metrics such as total pressure ratio and mass flow. This work used a non-intrusive probabilistic collocation method to simultaneously address geometrical and operational uncertainties as well as uncertainties resulting from manufacturing variability.

The Internal Aerodynamics team was led by C. Hirsch of Numeca International. Team members include C. Dineseu of Numeca International, S. Smrnov and C. Lacor of the University of Brussels. Summary results in these AIAA special sessions are provided by Nigro et al. ${ }^{8}$

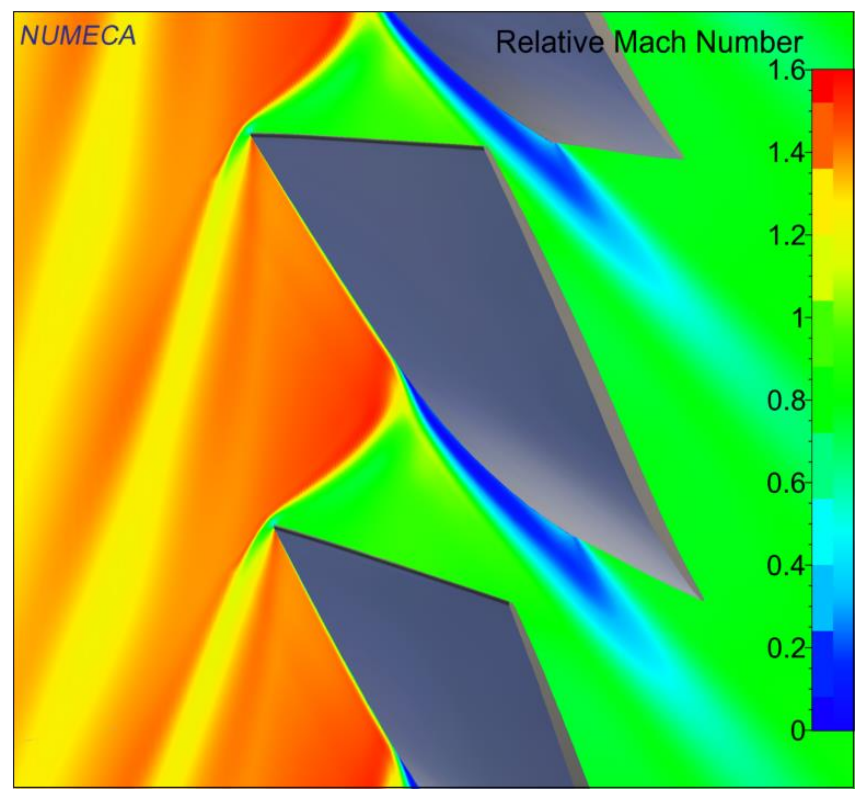

Figure 6. Deterministic rotor flow field simulation shown at a mid-span station on the rotor blade. Flow is from left to right.

\section{Aeroelasticity}

The aeroelastic team focused on determining and accounting for uncertainties in modeling an aeroelastic wind tunnel model. The model chosen was the NASA Langley Research Center (LaRC) S4t supersonic cruise configuration ${ }^{9}$ shown in Fig. 7. It is characterized by a long slender fuselage and a highly sweep, low aspect ratio wing. The model was extensively instrumented with unsteady pressure, structural acceleration, and load measurement devices. Figure 8 presents a conceptual drawing of the model with key components labeled; all structural components are metric. Data from the aeroelastic tests in the LaRC, Transonic Dynamics wind Tunnel (TDT) were available for comparison purposed.

An example of the S4T first natural mode of vibration of the baseline configuration, computed using a finite element



Figure 7. S4T aeroelastic wind tunnel model. method, is shown in Figure 9. This mode consists of pitch about the forward nodal mount with both wing bending and torsion. The figure illustrates that mode shapes for the configuration are more complex than simple beam or wing-alone modes; they include combinations of movement from several model components. The natural modes are appropriately scaled and combined, and the result is used to model the S4T structural response to aerodynamic loads imposed by the wind tunnel flow and/or loads computed from CFD simulations.

The objective of aeroelastics model problem study was to determine the effects of established variation in model simulation input parameters on important measured quantities such as aeroelasticity and flutter. The variable input quantities included in the analysis are structural properties such as Young's modulus and damping and wind tunnel variables such as Mach number, angle of attack, and dynamic pressure. The as-built model geometry was obtained by a laser scan of the outer mold lines. 
The Aeroelasticity Team was led by A. Cunningham of the Lockheed Martin Company. The team members included J. Heeg of NASA LaRC, M. Nikbay of the Istanbul Technical University, and J. Cooper of the University of Bristol, Queens School of Engineering. Summary results in these AIAA special sessions are provided by Cunningham and Holman ${ }^{10}$, Nikbay and Heeg ${ }^{11}$, and Tartaruga et al. ${ }^{12}$

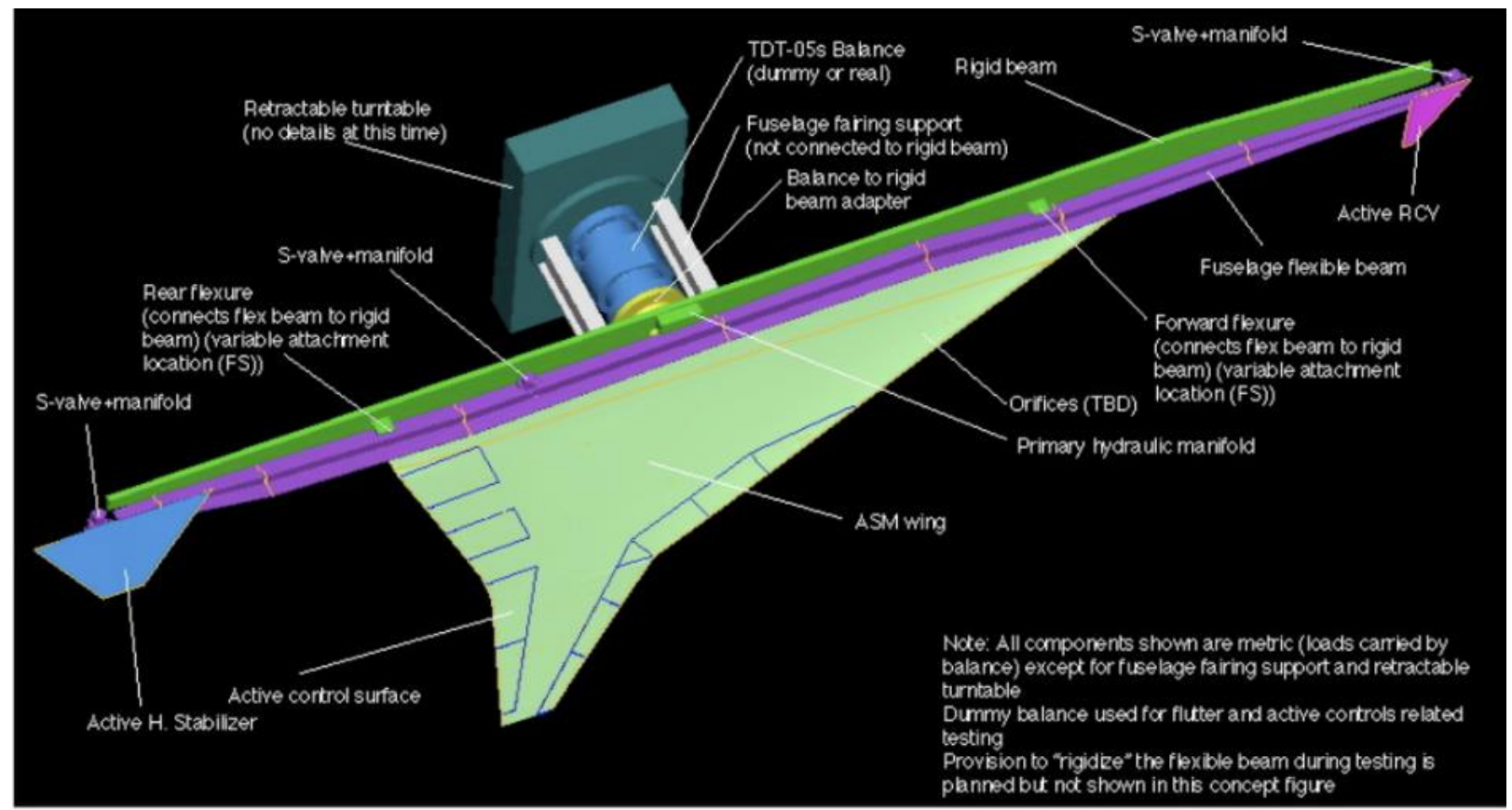

Figure 8. Conceptual drawing of $S^{4} t$ wind tunnel model.

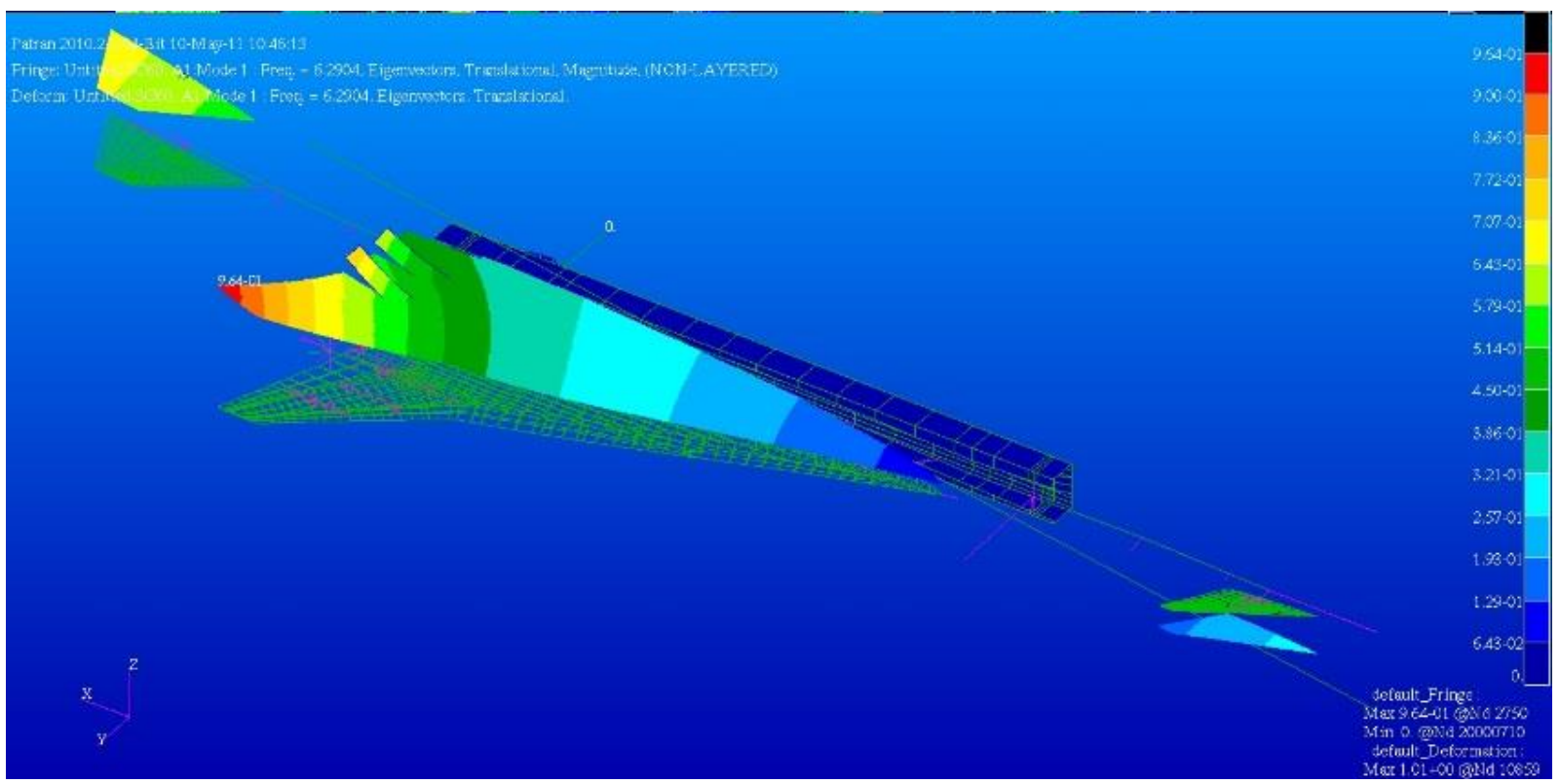

Figure 9. Computed first mode of vibration of baseline model.

(Sally-clearer figurer has been requested) 


\section{Hydrodynamics}

The Hydrodynamics Team's objective was to develop and apply efficient uncertainty quantification tools to realistic, industrial class ship hydrodynamic problems and to validate sensitivity analysis and uncertainty quantification methods for these problems. They focused on application of several uncertainty estimation methodologies including both deterministic and stochastic approaches. They considered the Delft, high speed catamaran configuration ${ }^{13}$ (See, Fig. 10.) operating in calm water and free to heave and pitch and in a Sea state 6 condition with head on waves. The variable inputs were the Froude number and wave height and period. Both flows had a mean Froude number of 0.5 . The effect of these variable input parameters on total resistance coefficient, sinkage, trim, $\mathrm{x}$-force mean and root-mean-square variation (rms), heave mean and rms, and pitch mean and rms were evaluated. Experimental data obtained by ISNEAN (National Research Council-Marine Technology Research

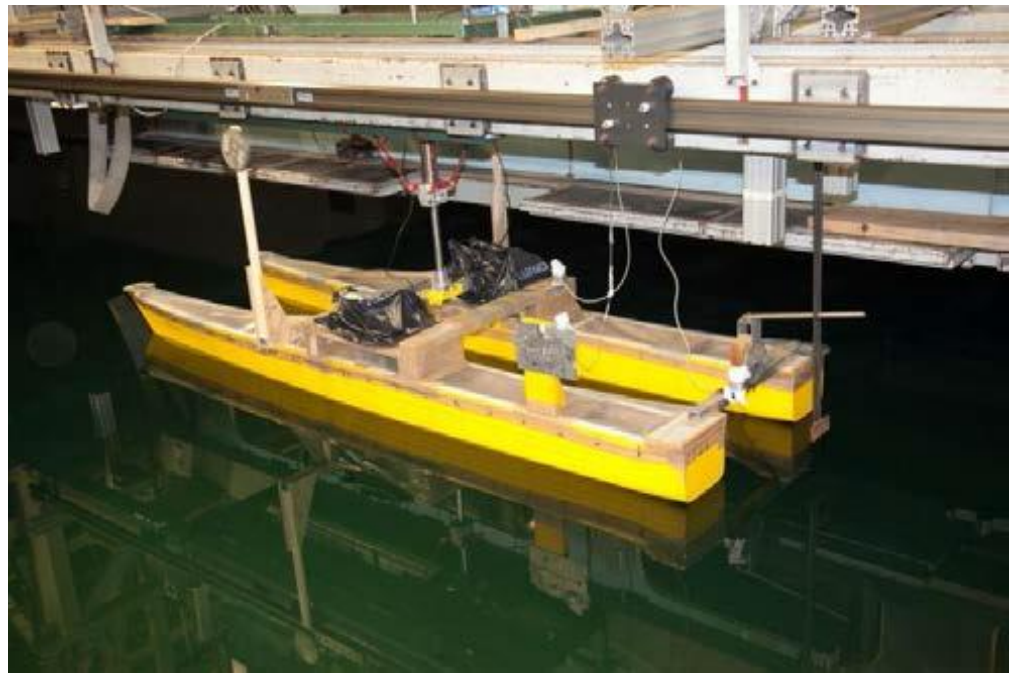

Figure 10. Delft high speed catamaran.

Institute) were used for comparison purposes. The complexity of the simulations used in this study is illustrated in Fig. 11. This simulation was made using a URANS CFD model in irregular waves which are constructed from linear combination of several wave components. These components interact in a non-linear manner to generate the irregular waves that interact with the catamaran model. The figure also illustrates the interaction of the waves with upstream and downstream hulls and the complex interaction of the waves downstream of the catamaran.

The Hydrodynamics Team was led by F. Stern, University of Iowa. Team members included M. Diez and E. Campana of CnR-INSEAN, and U. Iemma of the University of Rome. Summary results in these AIAA special sessions are provided by Stern et al. ${ }^{14}$, and Diez et al. $^{15}$

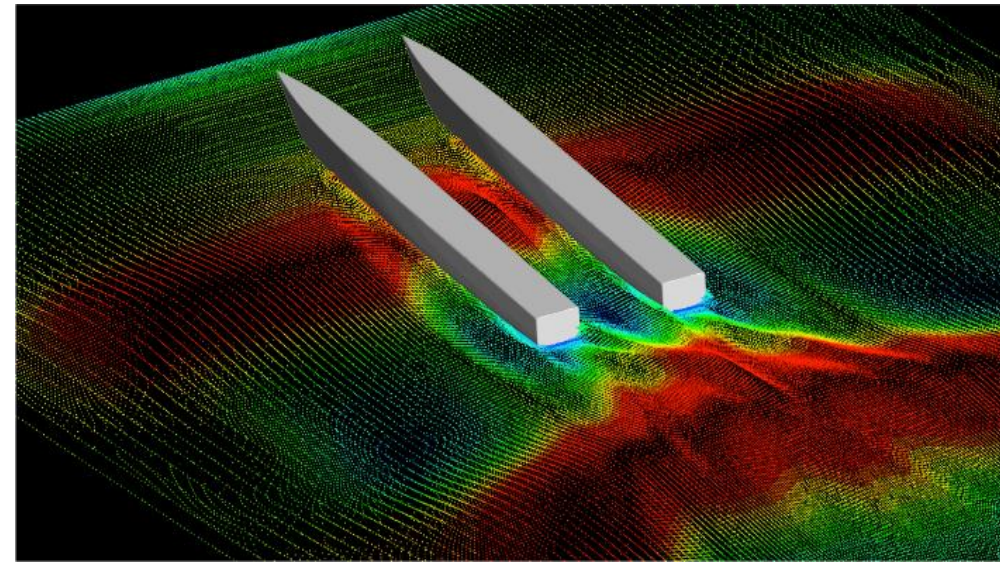

Figure 11. URANS simulation in irregular wave at sea state 6 and $\mathrm{Fr}=\mathbf{0 . 5}$.

\section{Concluding Remarks}

Task Group AVT-191 examined the maturity and usability of several SA/UQ methods by applying them to four representative areas for air and sea design issues: external aerodynamics, aeroelasticity, hydrodynamics, and internal aerodynamics. Representative configurations which had high quality experimental data for comparison were selected. Exercise of a variety of methods among the discipline teams revealed unanticipated difficulties, all of which were overcome. The development of reduced order models was found to significantly reduce the resources required to apply many of the selected sampling methods.

The overarching result of this study is that many SA/UQ methods can be used directly with minor, problem dependent modification. There are a number of sources for vetted SA/UQ application software that allows practitioners to avoid extensive method development. However, it is incumbent upon the user to thoroughly understand the methods chosen to employ for a specific analysis and to carefully verify the computed results. 


\section{References}

${ }^{1}$ RTO, “Computational Uncertainty in Military Vehicle Design,” RTO-MP-AVT-147, 2008.

${ }^{2}$ STO, "Reliable Prediction of Separated Flow Onset and Progression for Air and Sea Vehicles," STO-TR-AVT-191, to be published.

${ }^{3}$ FG5 generic missile configuration data supplied to AVT 191 by Applied Aerodynamics Department of ONERA.

${ }^{4}$ Peter, J., Gortz, S., and Graves, R., “Three-parameter uncertainty quantification for generic missile FG5,” AIAA Paper 2017xxxx, January 2017.

${ }^{5}$ Doty, J. H., “Meta-Model Results For Polynomial Chaos Method,” AIAA Paper 2017-xxxx, January 2017

${ }^{6}$ Graves, R., “Scalable Uncertainty Taxonomy for a Transonic Missile,” AIAA Paper 2017-xxxx, January 2017

${ }^{7}$ Dunham, J., “CFD validation for propulsion system components,” AGARD-AR-355, 1998.

${ }^{8}$ Nigro, R., Wunsch, D., Coussement, G., and Hirsch, C., "Uncertainty quantification in internal flows," AIAA Paper 2017-xxxx, January, 2017.

${ }^{9}$ Silva, W. A., Perry, B., Florance, J. R., Sanetrik, M. D., Wieseman, C. D., Stevens, W. L., Funk, C. J., Hur, J., Christhilf, D. M., Coulson, D. A., "An Overview of the Semi-Span Super-Sonic Transport $\left(\mathrm{S}^{4} \mathrm{~T}\right)$ Wind-Tunnel Model Program", AIAA paper 2012-1552, April 2012.

${ }^{10}$ Cunningham, A. M. Jr., and Holman, R. J., "Studies of Aeroelastic Uncertainty Quantification for a Wind Tunnel Model and Test Program - Overview and Static Aeroelastic Analysis,” AIAA Paper 2017-xxxx, January 2017

${ }^{11}$ Nikbay, M., and Heeg, J., "Aeroelastic uncertainty quantification studies using the S4T Tunnel Model," AIAA Paper 2017xxxx, January 2017.

12 Tartaruga, I., Cooper. J., Georgiou, G., and Khodaparast, H. H. "Flutter Uncertainty Quantification for the S4T Model," AIAA Paper 2017-xxxx, January 2017

${ }^{13}$ Diez, M., He, W., Campana, E. F., Stern, F., "Uncertainty quantification of Delft catamaran resistance, sinkage and trim for variable Froude number and geometry using metamodels, quadrature and Karhumen-Loeve expansion", J. Mar Sci Technol (2014) 19: 143-169.

${ }^{14}$ Stern, F., Volpi, S., Gaul, N. J., Choi, K. K., Diez, M., Broglia, R., Durante, D., and Campana, E. F., "Development and Evaluation of Uncertainty Quantification Methods for Ship Hydrodynamics: an Overview," AIAA Paper 2017-xxxx, January 2017

${ }^{15}$ Diez, M., Broglia, R., Durante, D., Olivieri, A., Campana, E. F., and Stern, F., "High-Fidelity Uncertainty Quantification and Validation Methods for Ships in Irregular Waves,” AIAA Paper 2017-xxxx, January 2017 